توقعات إعلامية؛ بلاغة الخطاب الإقناعي

\title{
Media Expectations; The Rhetoric of Persuasive Speech
}

\author{
Haruna Umar Farouq ${ }^{1}$, Mat Taib bin $\mathrm{Pa}^{2}$ \\ ${ }^{1}$ Al-Hikmah University, Ilorin, Nigeria, \\ ${ }^{2}$ Faculty of Languages and Linguistic, Universiti Malaya, Malaysia \\ farouqumar1@yahoo.com,mattaib@um.edu.my
}

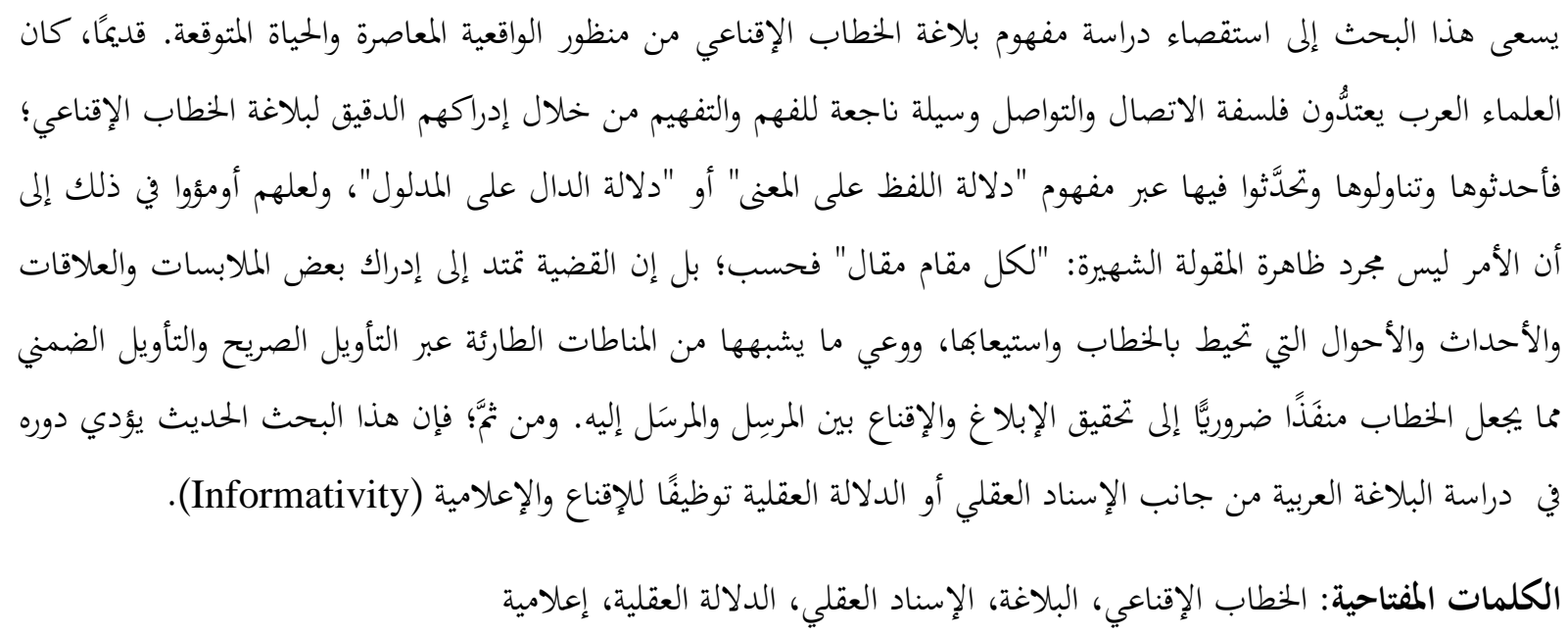

\section{Abstract}

The goal of this study is to look into the concept of persuasive rhetoric from the perspective of current realism and life expectations. In the past, Arab scholars used communication and comprehension philosophy as an effective means of understanding and comprehending through accurate awareness of the eloquence of persuasive discourse; thus, they initiated, developed, and engaged with it through the concept of the terms; "the signification of the word on the meaning" or "the signification of the signifier (Ad-daal) on the eloquence of persuasive discourse." The argument applies to awareness and understanding of some of the circumstances, relationships, events, and conditions surrounding the persuasive discourse, as well as awareness of similar emergency conditions through explicit and implicit interpretation, making the persuasive discourse a necessary outlet for reporting and persuasion between the sender and the addressee. As a result, this current study contributes to the study of Arabic rhetoric from the perspective of mental attribution or mental importance, employing persuasion and informative techniques.

Keywords: Arabic Rhetoric, Persuasive Discourse, Explicit Interpretation, Implicit Interpretation, Informative

Article History:

Received: 7/10/2021 Accepted: 16/10/2021
Published: 10/11/2021 
DOI: https://doi.org/10.22452/aldad.vol5no1.8 e-ISSN: 2637-1146

https://ejournal.um.edu.my/index.php/aldaad/index

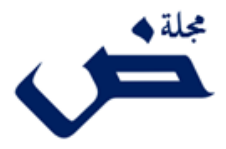

المقدمة

الإعلامية بوصفها معيارًا من معايير النصية تؤدي دورًا راسخًا في تبليغ الرسائل اللغوية والأدبية، وهي بوصفها أيضًا وسيلة من وسائل التحليل اللغوي الحديث تمثّل عنصرًا ملموسًا في رسم الدراسة البعيد المدى في البلاغة والإقناع. ' والعبارة "البعيد المدى في البلاغة والإقناع" الواردة في هذا السياق يوحي أن الدراسة التي سيتناوها هذا البحث لا لا فئس

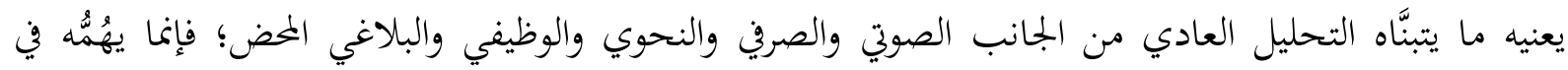
إطار هذه الدراسة رسم كل ما في إمكانيته أن يجعل الخطاب بالغًا للغاية المرجوة ومفهومًا فهمًا واعيًا.

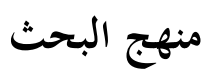

لقد تتبع الباحث المنهج الوصفي التحليلي خلال دراسته لهذا الموضوع من حيث الدراسات البلاغية واللغوية ولما

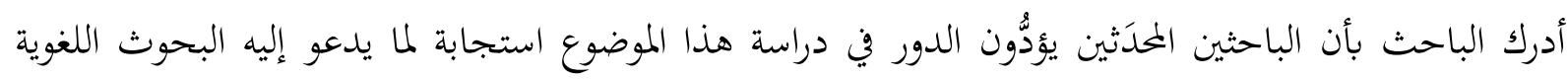
الحديثة. ثم إن هذه الورقة ستدرس بلاغة الخطاب الإقناعي عبر معيار الإعلامية، متوخية في ذلك المرور بالمعلومات.

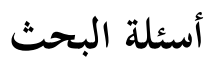

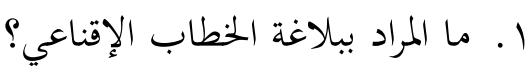

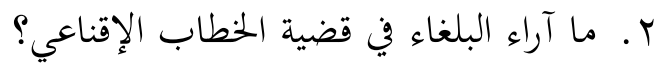
ب. بـ ما علاقة الإسناد العقلي بالدلالة العقلية؟

\section{أولاً: دلالة اللفظ على المعنى أو دلالة الدال على المدلول}

يرى العلماء المتقدمون من المتكلمين والبلاغيين واللغويين والفقهاء والأصوليين والفلاسفة أن دلالة اللفظ على المعنى أو إسناد لفظ مخصوص إلى معنى مخصوص يعد محل دراسة بارزة في الحقل اللغوي خاصة في علم المعاني

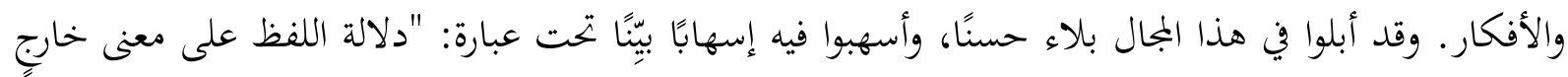

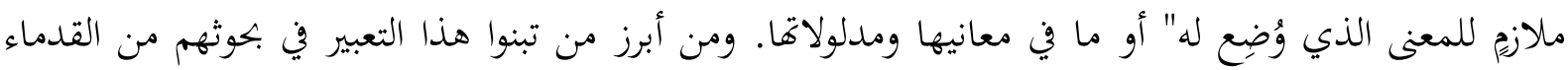

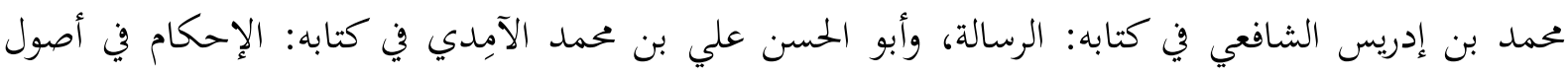
' أمد عفيفي، خو النص: اتجاه جديد في الدرس النحوي، (القاهرة: مكتبة زهراء الشرق، طا، ال. بم)، صVV. 
الأحكام، والقرافي في كتابه: شرح تنقيح الفصول، وإبراهيم بن موسى الشاطبي في كتابه: الموافقات في أصول

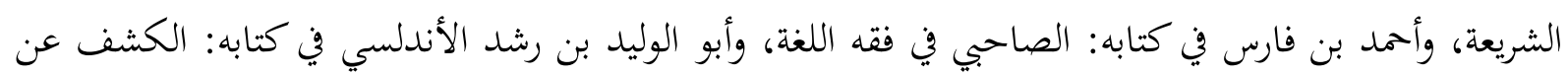

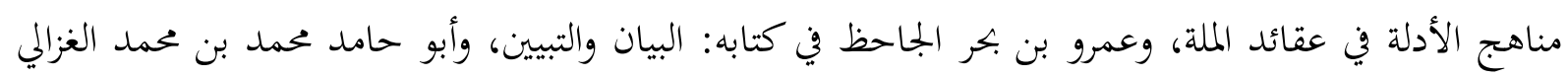

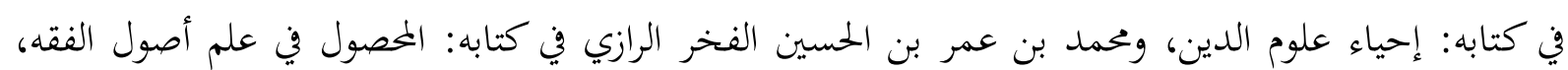
ومحمد الطاهر ابن عاشور في كتابه: مقاصد الشريعة الإسلامية.

لقد اشتهر البحث في هذا العنوان لدى هؤلاء العلماء وغيرهم من المتأخرين بدلالة الالتزامَ أو ما يعرف بعبارة

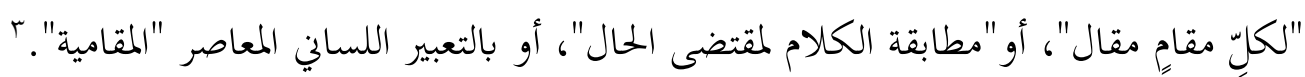

ومهما يكن من أمر دلالة اللفظ على المعنى، فإن ثمة ملابساتٍ وأوضاعًا وأحوالا وعلائقَّ بتعل الخطاب صالحًا

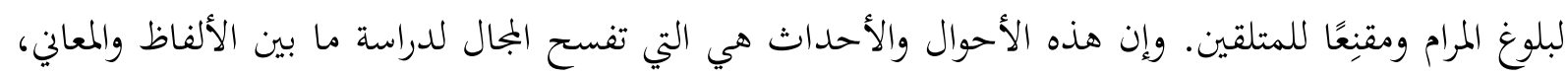

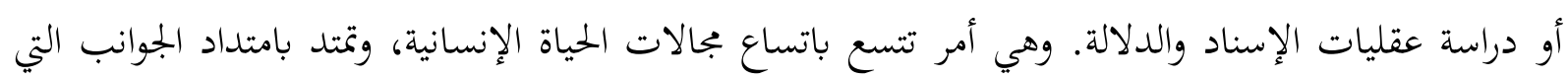
ينبغي أن يرتبط بها الأحوال الشخصية.

\section{ثانيًا: دراسة الإسناد والمناطات أو الأحوال التي تحيط بالخطاب لدى القزويني}

يعد الخطيب القزويني من أبرز العلماء الذين تعمقوا في دراسة الدلالة أو الإسناد، وأسسوا عبارة "البماز العقلي".

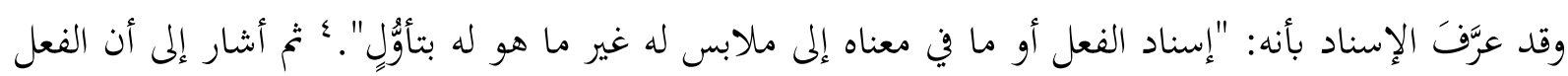
يتميز بمختلف الأحوال والملابسات حيث يمكن الوصول بتفعيل أفعال الكلام إلى تحصيل الأشياء الآتية واستباطها من الكلام: nميز

$$
\begin{aligned}
& \text { (أ) المتكلم - الفاعل أو مرِسل الخطاب } \\
& \text { (ب) المخاطب - المفعول به أو مستقبِل الخطاب } \\
& \text { (ج) الوقائع والأحداث - المصدر }
\end{aligned}
$$

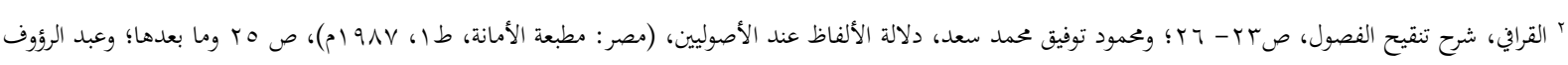

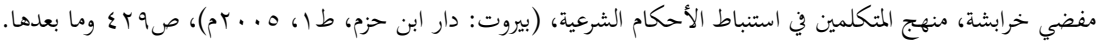

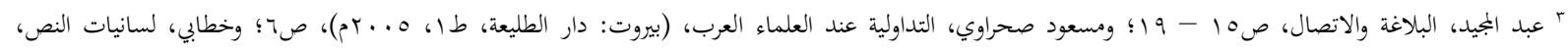

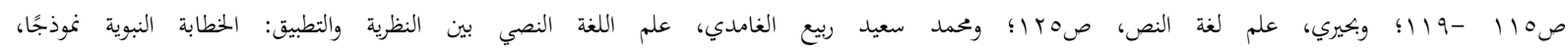
(Www.mohamedrabeea.com

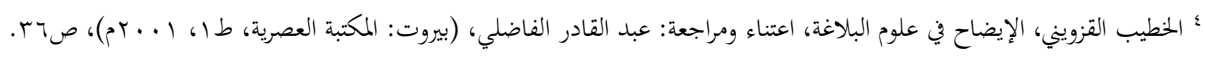


DOI: https://doi.org/10.22452/aldad.vol5no1.8

e-ISSN: 2637-1146

https://ejournal.um.edu.my/index.php/aldaad/index

$$
\begin{aligned}
& \text { (د) الحين أو الحال - الزمان } \\
& \text { (ه) المقام أو الموقع - المكان } \\
& \text { (و) العوامل أو الظروف - السبب }
\end{aligned}
$$

لقد عمل القزويني على أن طرفي الملابسة إما أن يوجدا بين الفاعل المجازي والمسند وإما بين المسند إليه المجازي والمسند إليه الحقيقي - مثل قول القائل: بنى عمرو بن العاص مدينة الفسطاط؛ إذ إن عمرو بن العاص فاعل بجاٍٍ

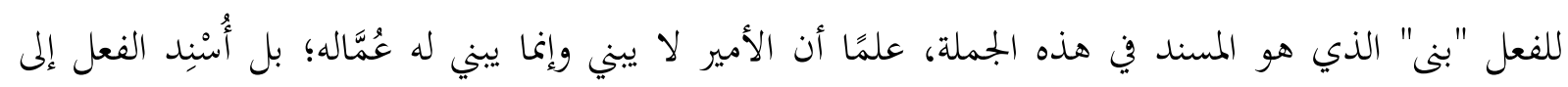
الأمير مجازًا، فالأمير هو المسند إليه المجازي والعمَّال هم المسند إليه الحقيقي. ومن ثتََّّ لا ينبغي للمتلقي أن يرفض حقيقة هذا الكلام إذ لا يتم بناء هذه المدينة وإنشاؤها في الحقيقة دون موافقة الأمير ونفوذه وإذنه أو تصريحه الراسخ. ولا ريب أن الدلالة أو الإسناد في هذا السياق يدرك بالعقل، كما يمكن إدراك الإسناد المجازي مصدر الفعل أو زمانه أو مكانه أو سببه أو غير ذلك مما يُعمِل الإنسان فيه العقل والذكاء. ولا يجدي ذلك إلا بإعلام المخاطب بما ينبغي أن يحيط بهذا الخطاب من علاقات وأحداث ومناطات وأحوال تؤسس ضرورة الاقتناع والإيمان بحقيقة ما يصل إليه بتأوَّلٍ. أما الحقيقة العقلية فقد عرَّفها القزويني بقوله: "هي إسناد الفعل أو ما في معناه إلى ما هو له عند المتكلِّم في الظاهر".

ومن هنا ينجح الخطيب القزويني في إرساء فكرة الإسناد أو المجاز العقلي الذي استعرضنا تعريفه سابقًا بعبارته. ويف هذا يرى د.ك أبو موسى أنه على الرغم من مختلف آراء البلاغيين في ضبط طريف الملابسة بين المسند إليه المجازي والمسند إليه الحقيقي، فإن دراسة الإسناد مع الملابسات والعلاقات التي تدور حول خطابٍ ما من أجلِّ الدراسات اللسانية وأطرفها في دراسة الأسلوبية والتحليل. ج وقد تناوله أبو موسى هذا البيان بالتفصيل تحت الموضوع "التجَوُّز في الإسناد". \ ولعل أبا موسى يرى هذا الرأي لاعتناء دراسة الأسلوبية والتحليل بتبيين أشياءَ لها وشائج وصلات مع الخطاب المعني، وبيان كيفية تصور هذه الوشائج والصلات في ذهن المتلقي وتخيُّلها بخيال تصويري رائع متقارب، بحيث لا يرفض حقيقته حِجا ولا يفنِّ صحته لُُّّ. 
DOI: https://doi.org/10.22452/aldad.vol5no1.8

e-ISSN: 2637-1146

https://ejournal.um.edu.my/index.php/aldaad/index

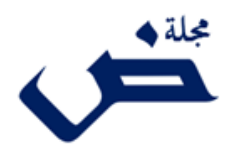

ثالثًا: إسهام الجرجاني في بلاغة الحطاب وإقناعه

إن مما رفع شأن عبد القاهر الجرجاني وأشاع صيته بين قدامى اللغويين والبلاغيين كتابه "دلائل الإعجاز في علم المعاني". ويعد الجرجاني من أبرز العلماء الذين حافظوا على ميزات اللغة العربية، وضمَّنوا لها الفصاحة والبلاغة والإقناع. ولقد سجل المتقدمون والمتأخرون الفضل السابق للجرجاني في وضع أسس التحليل اللغوي لإلقاء الضوء على ما يعبّرِ عنه الإنسان من نصِّ مَقُولٍٍ أو مكتوبٍ عبر ما سمَّاه بنظرية النظم؛ إذ يقول: "إن هذه المزايا في النظم، بحسب المعاني والأغراض التي تؤمُّه..." وإنه بهذه الفكرة يرى ضرورة الاعتبار والخضوع لكل ما يتجدد من الأوضاع والأحوال والظروف والخطوب لنتمكن من تبليغ رسالة خطابٍ ما وتفعيل إقناعيته عند كل سامع أو قارئ. ثم إنه يرى أن هذه المستجدات كثيرة لا يمكن تحديد كنهها أو منتهاها نظرًا إلى تنويع وقائع الحياة وأحداث الزمان؛ فالوجوه التي يمر بها الأمور تزداد ازديادًا لا يُنْهَى.

فلعل ابتحاه التحليل اللغوي عند الجرجاني لا يتقيد بالضوابط النحوية والقواعد البلاغية المحضة؛ بل ينبغي أن يتحلى بميزة التبليغ العصري والإقناع، ولا يتم ذلك إلا إذا أظهر الإنسان ديناميكية العقل باعتباره أداة العمل الإجرائي الناجع التي تتغير بتغير الواقعية التي نعيشها أو نتعامل معها، وكذلك باعتبار معاني الخطاب أو الأغراض التي يرنو إليها بأهما السلسلة الاتصالية المتواصلة التي لا تنقطع؛ إذ إها تراد مناسبة للوقائع الراهنة، وتُستعرضض ملاءمة للأفكار الأخرى التي تمت إليها بصلة. 9

وهنا يرسي الجرجاني أن للعقل البشري دورًا بارزًا يؤديه عند استقبال الخطاب المكتوب أو الملفوظ، وأن القارئ أو السامع بهذا الدور الملموس هو المؤلف الخارجي للخطاب، وهو المسؤول عن ما توصل إليه الخطاب أو ما ينبغي أن يتوصل إليه من الدرجة الرفيعة إلى الإبلاغ والإقناع والتواصل، وأنه بواسطة ذكائه الدينامكي العظيم يتلقى الخطاب وينظر إليه ويفحصه ويتدبره ويدبِّره تدبيرًا حسنًا؛ فيدرك أن من طبيعة الأصوات اللغوية أن تخضع للمعاني والأفكار وتتابعها وتتماشى معها في الابحاه السديد دون العكس. ‘' وكأن الجرجاني بهذا المفهوم يعُدٌّ مرسلَ الخطاب أو ملقيَه صاحب الفضل السابق في الاختراع وخلق الخطاب، وهو إذن مجرد المؤلف الداخلي له، وهو صاحب معانيه السائلة؛ لأنه يستقصي قراءته ويبحث له معاني ضمنية متقدمة، يستنبطها عبر ثقافاته المتنوعة

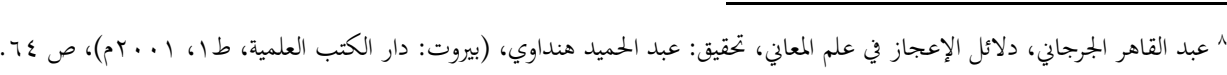

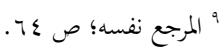

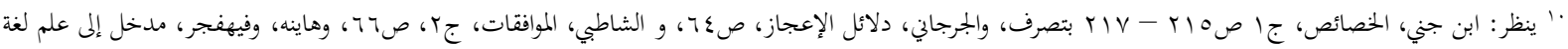


DOI: https://doi.org/10.22452/aldad.vol5no1.8 e-ISSN: 2637-1146

https://ejournal.um.edu.my/index.php/aldaad/index

المكتسبة والمتأصلة، تاريخيَّا وواقعيَّا وعلميَّا وأدبيَّا وحاليَّا ومقاميًّا. " فالمؤلف الخارجي هو صاحب المعاني الصلبة ir

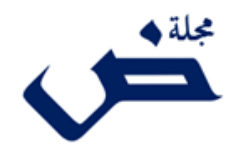
وفق تعبير جـ مصطفى ناصف. '

ومن واجبات المؤلف الداخلي أن يؤسس النظم اللغوي الناجع للخطاب، وأن يراعي فيه الاتساق والانسجام أولاً وقبل أن يباشر العمل الدقيق في إجراءات وضع البنية اللغوية الصغرى للخطاب أو في إبراز المعاني الصريحة له.

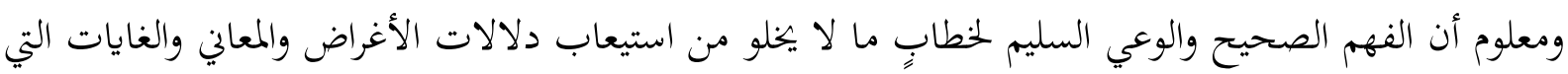

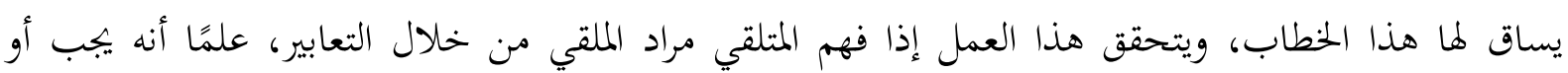

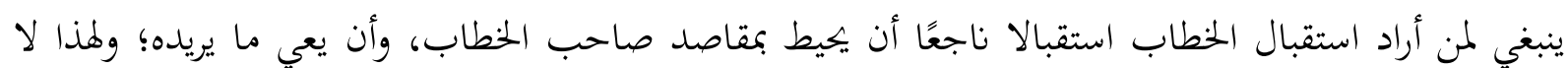

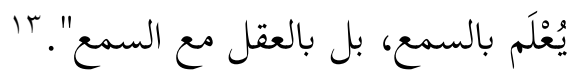

\section{رابعًا: نبذة من وجهة نظر بعض اللسانيين المُحدَثَين}

وإذا ثبت أن من وظائف أفعال الكلام أن تتسم إعلامية الخطاب وإقناعه للمتلقي بحركة ديناميكية العقل والذكاء

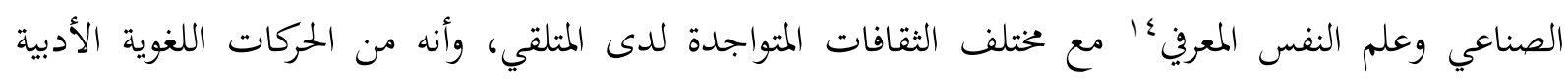

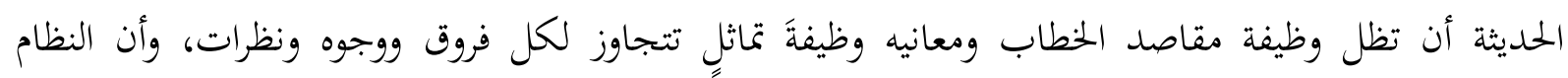

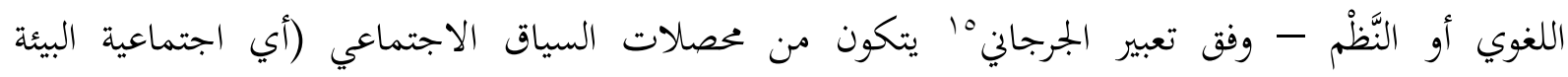

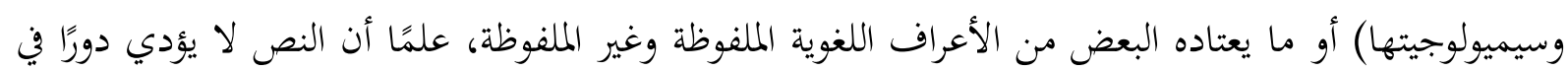

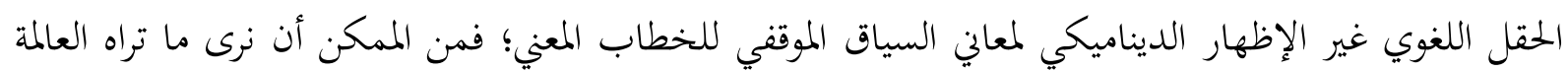

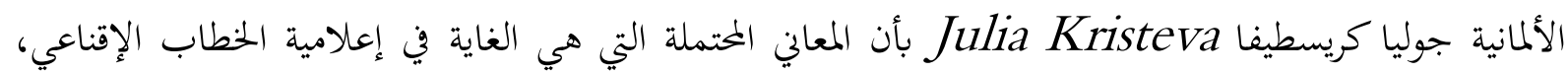
ومن سمات قوة هذه المعاني أها تتغير وفق الأوضاع والموافق التي تسود بمختلف وجهات نظر القارئين والسامعين والناظرين في شفرات الخطاب. ويمكن الإثبات أيضًا بعد إمعان النظر أن هذه المعاني مع الألفاظ التي تدل عليها

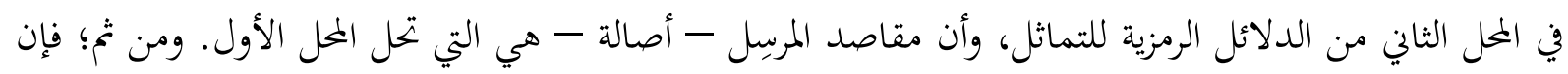

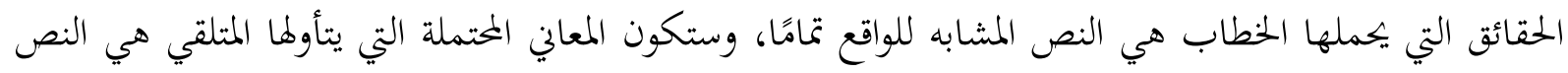

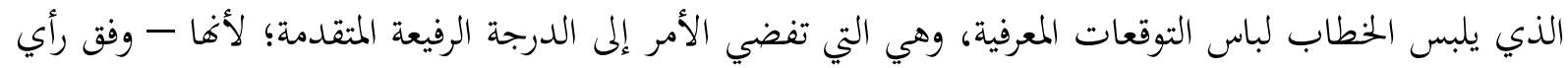

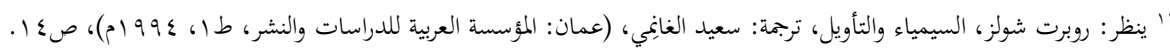

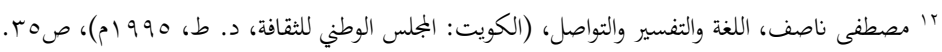

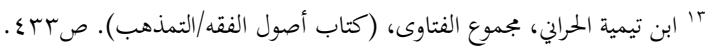

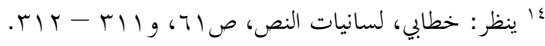

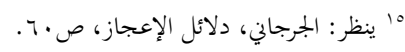


DOI: https://doi.org/10.22452/aldad.vol5no1.8 e-ISSN: 2637-1146

https://ejournal.um.edu.my/index.php/aldaad/index

كريسكيفا - غير ثابتة لا تملك خاصية واحدة بل هي متداولة"1 مع تداول الآراء والأفكار والنظرات ومختلف

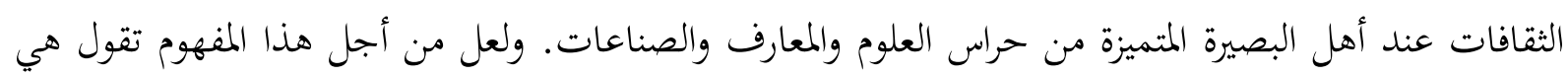

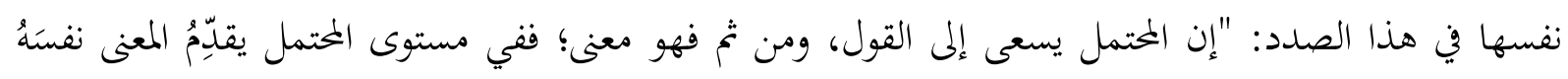

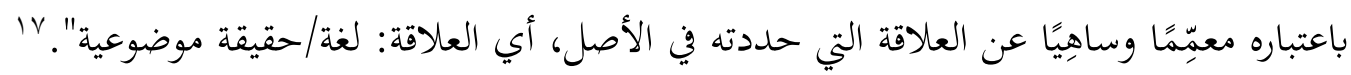

ومن هذا المنطلق يرى الباحث ضرورة تحري تفعيل التواصل أو تكوين العلاقة الودية المتواصلة بين الخطباء أو

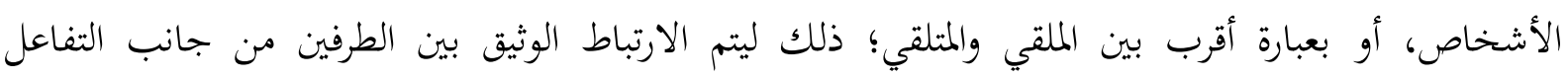

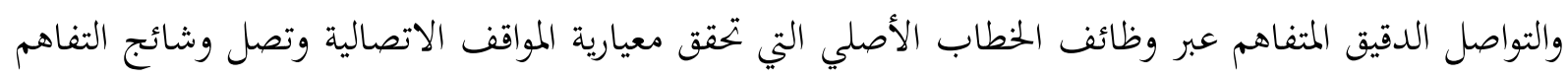

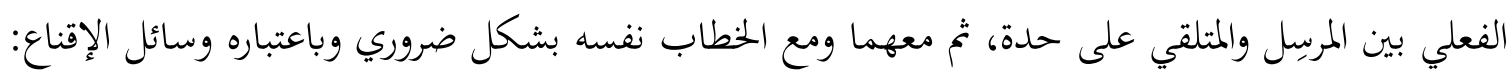
(أ) وسيلة الإعلام والإبلاغ حيث يتمكن الملقي من إعلام متلقي رسالته وتزويده بمعرفة ما، بأنه أراد أن يبِّغِغ

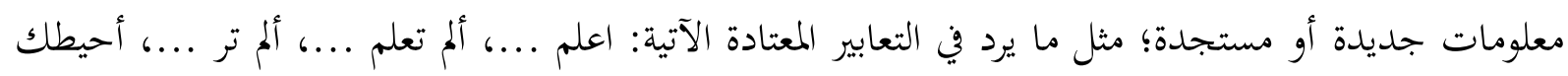

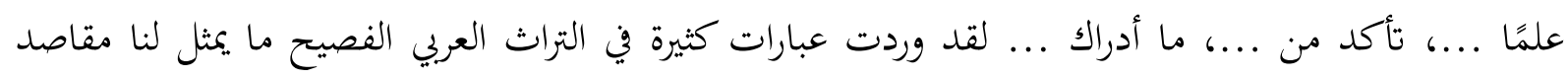

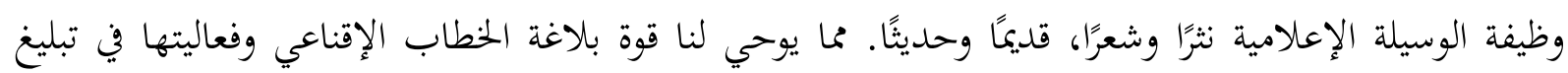

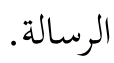

(ب) وسيلة الاستثارة هي التي تبرز التوافق بين صاحب الخطاب ومتلقيه، ويثير في القارئ أو السامع همة الرغبة

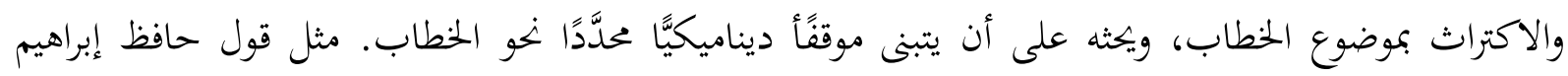

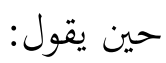

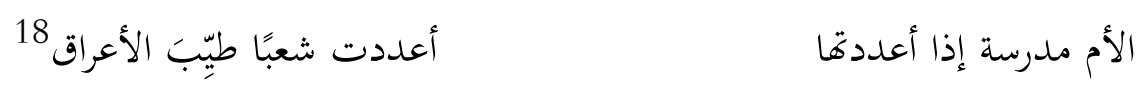

فالشاعر يحث الناس على الاهتمام بشأن الأنثى، ويحرضهم على التخاذ موقف خاص في إعدادها إعدادًا يبلغها الكمال في القوة والتربية والتعليه، حيث تكون صالحة لأداء المهمة المنوطة بها في توجيه الناشئ وتكوينه وتربيته

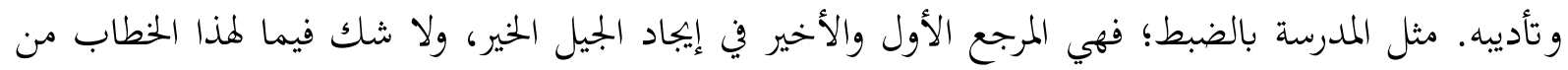

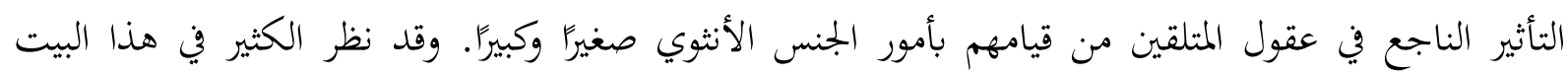

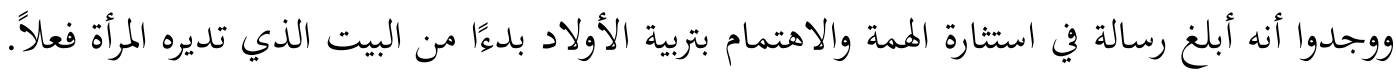

$$
\text { "1" "ينظر: كريسطيفا، علم النص، ترجمة فريد الزاهي، (المغرب: دار توبقال للنشر، ط 1، 1991 (م)، صهـ؛. }
$$


DOI: https://doi.org/10.22452/aldad.vol5no1.8 e-ISSN: 2637-1146

https://ejournal.um.edu.my/index.php/aldaad/index

(ج) وسيلة الالتزام؛ أما التزامية الخطاب الإقناعي فيتضح فيما إذا قصد الملقي إلزام متلقي خطابه القيام بأمر ما أو إنجاز عمل معيَّن، وذلك في مثل ما يرد في العقود والاتفاقيات والعهود وما يشبهها من العلاقات الفوزية

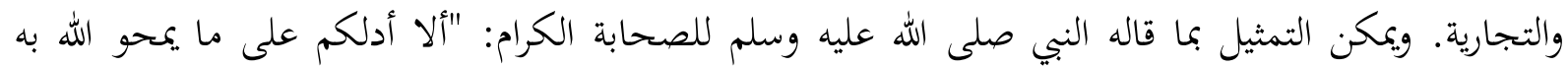

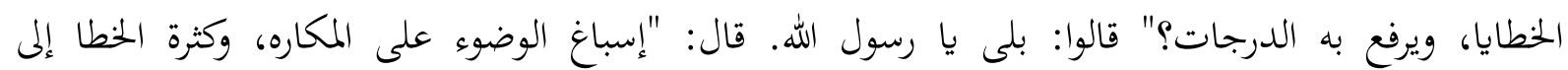

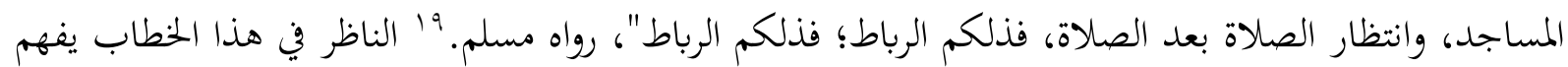
أن النبي صلى الله عليه وسلم يحاول إلزام المتلقين بأعمال معينة، وهي بمثابة أعمال التبادل التجاري لمن قام بها،

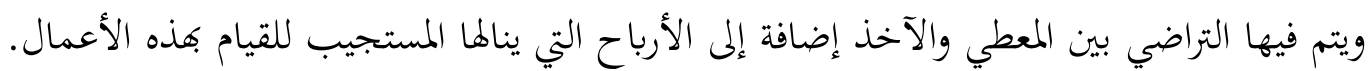

(د) وسيلة الاتصال؛ كون هذه الوسيلة يتطلب التعبير عن الموقف النفسي عند صاحب الخطاب نفسه، بأن يعبر عما يجيش في خاطره من الحزن والسرور والشكوى والرضا والتهئة والشكر والتقدير والتعزية والعتذار والدعوة وما يشبه ذلك. وأمثال هذه التعابير كثيرة في النصوص العربية شعرها ونثرها.

(ه) وسيلة الإعلان: لعل هذه الوسيلة هي الأهم في إطار هذا البحث. وقد أبلى اللغويون المحَدثون في دراستها

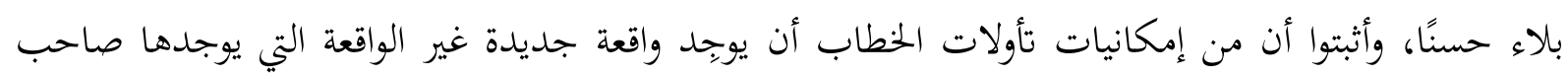
الخطاب نفسه، وكما يمكن أن ترتبط مفاهيم الخطاب بقضايا اجتماعية معينة، تسم بقداسة ثابتة وصراحة متحولة.

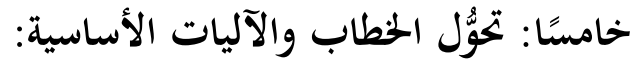

معلوم أن السامع أو القارئ العاقل لا يستقبل الخطاب إلا على صفحة جاهزة موهوبة بخبرات وبحارب اجتماعية

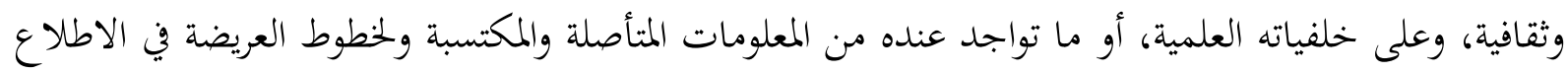
والاستقراء المزمع في تناول الأمور ومعالجة المسائل والقضايا والبحث عن الحلول لمختلف المشاكل. وعلى هذا

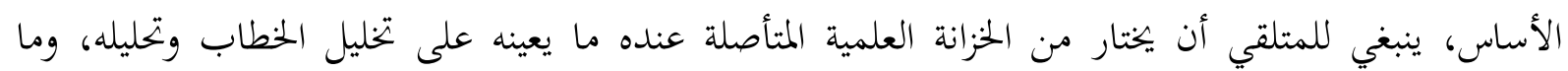

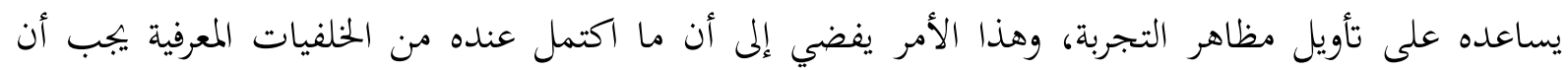
يكون بشكل مؤتمن مضبوط ومنتظم.

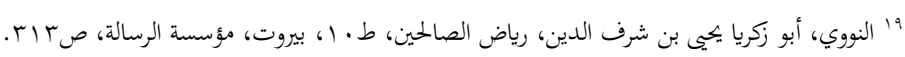

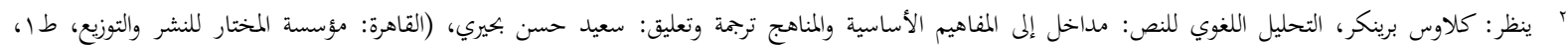

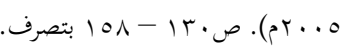


DOI: https://doi.org/10.22452/aldad.vol5no1.8 e-ISSN: 2637-1146

https://ejournal.um.edu.my/index.php/aldaad/index

ولعل هذا ما يجعل اللسانيين المحدثين يعتبرون المحصلات المعرفية أليات أساسية جاهزة في ذاكرة الإنسان؛ ليظل

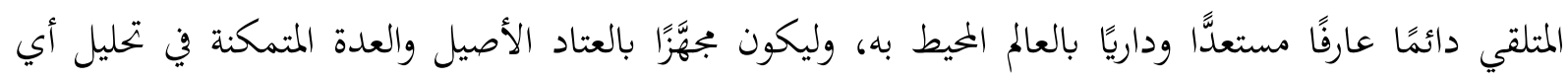
خطاب يفاجئه في الحياة. وقد اصطلح اللسانيون المحدثون على تدقيق عملية التحليل اللغوي في مجالين مهمين؛ هما: الذكاء الاصطناعي وعلم النفس المعريف.ب ومن ثم، لقد اجتهد علماء البشر في دراسة المقارنة بين خزانة

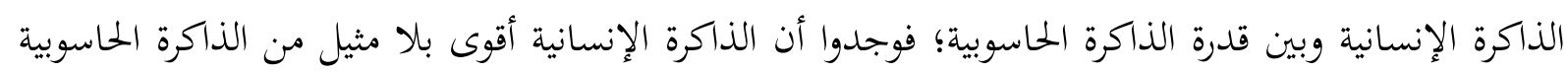

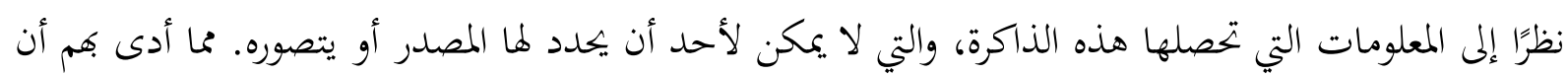

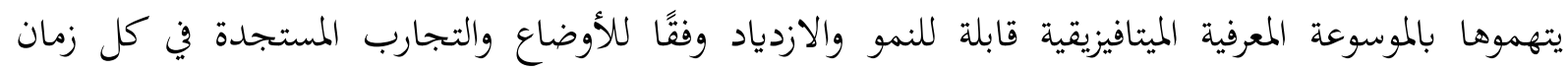

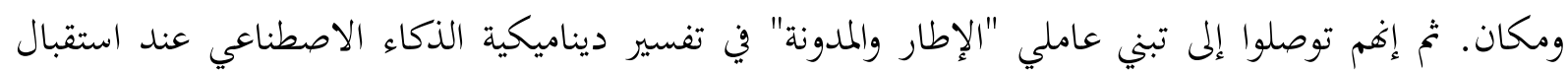

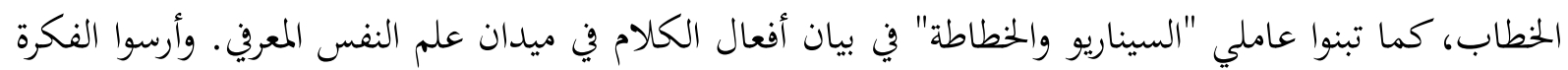

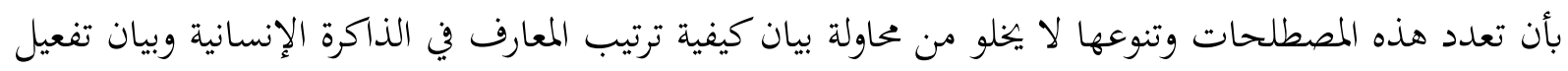

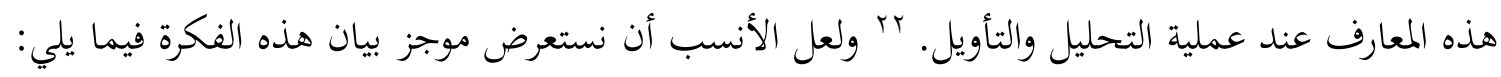
(أ) الإطار: وضعه مينسكي Minsky؛ ليؤسس أن ثمة معطيات معرفية أو وضعيات جاهزة في ذاكرة الإنسان،

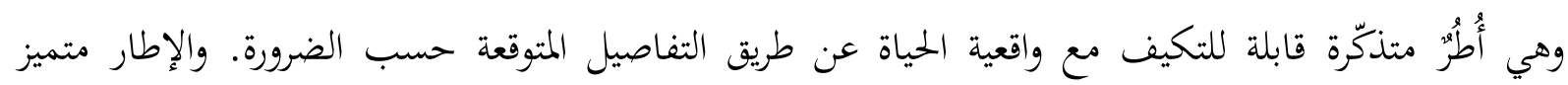

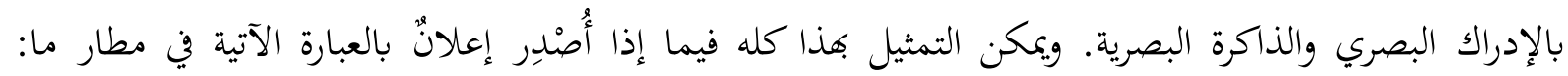
"يجب على جميع الركاب الحضور المبكر بالساعتين على الأقل قبل وقت إقلاع الطائرة". يدرك المتلقي أن إطار

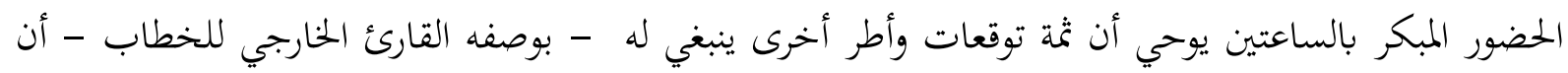

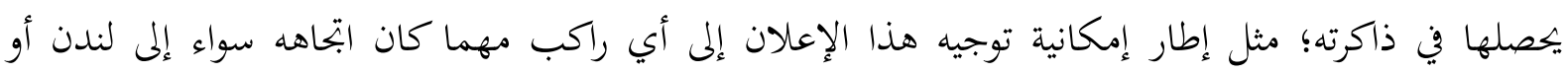

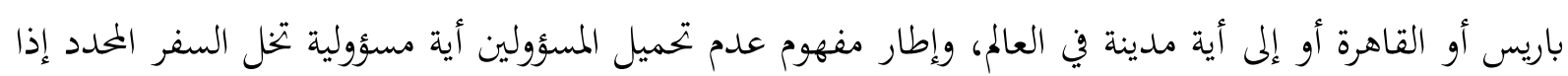

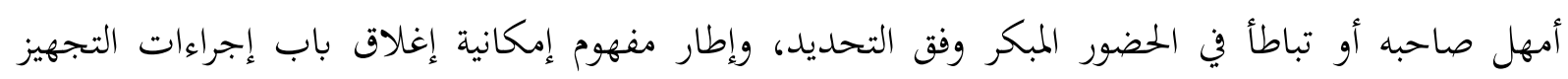

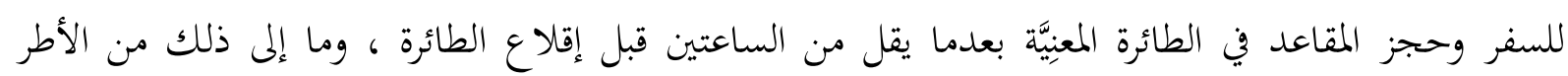

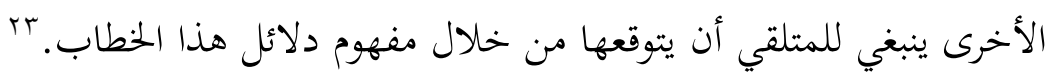

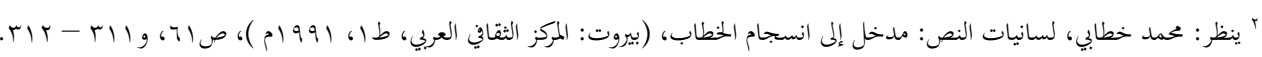

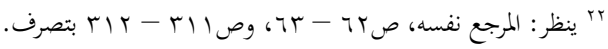

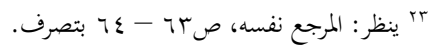


DOI: https://doi.org/10.22452/aldad.vol5no1.8 e-ISSN: 2637-1146

https://ejournal.um.edu.my/index.php/aldaad/index

(ب) المدوَّنة: مفهوم المدونة عند اللسانيين يختلف نوعًا ما عن الإطار. ذلك أن الإطار حينما ييحث في توقعات ووضعيات جاهزة في الذاكرة الإنسانية، فإن المدونة تلعب الدور في البحث في التبعيات المفهومة وفق دلالات

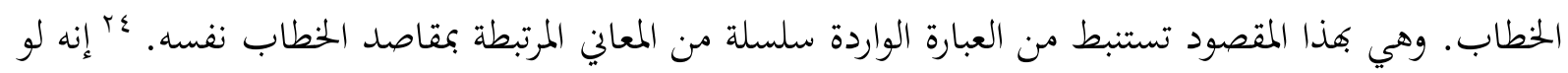

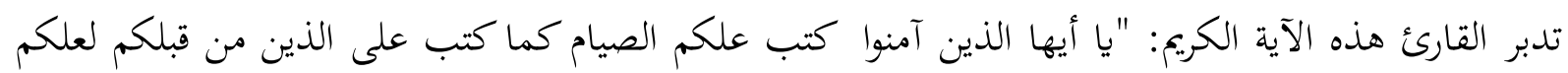

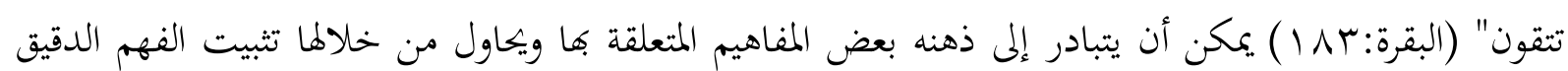

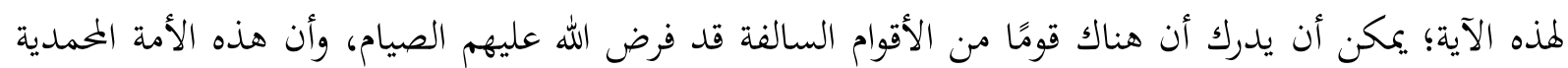

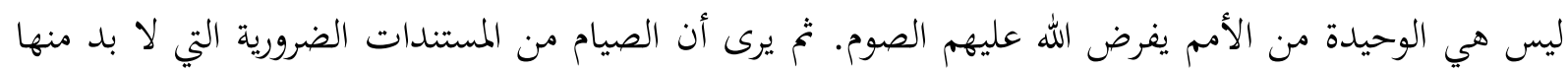

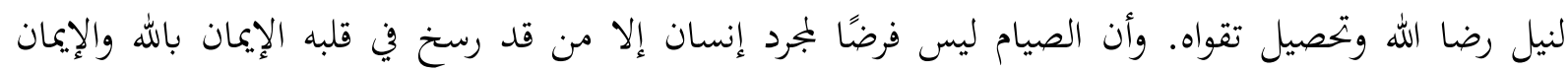

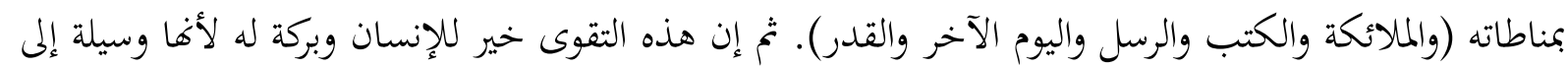
اكتساب رضوان الله تعالى في الدنيا والآخرة. وغير ذلك من المفاهيم المدونة في خزانة الذكاء الاصطناعي عند

(ج) السيناريو: يبدو أن هذا اللفظ تعريب من الكلمة الإنجليزية "Scenario" ويعني بيان الموقف أو البمال

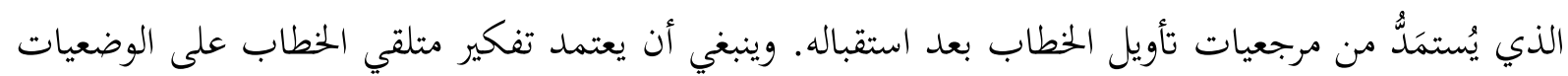

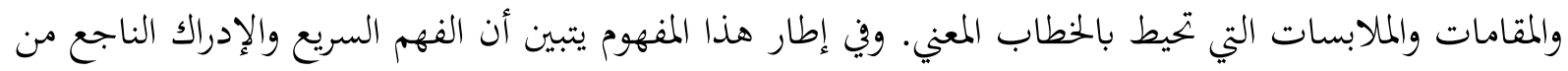

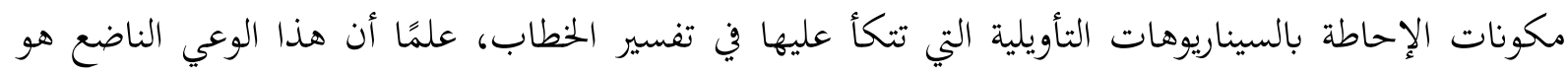
الدليل على قوة ذهن المتلقي وقدرته الأصيلة المرتبطة إلى مدى بعيد بتفعيل السيناريو الملائم. ثم إن نشاط هذا العامل السيناريوي يبرز عن طريق فاعلية الملقي وتمكن المتلقي على تبيين وجوه السيناريوهات المختلفة.

(د) الحطاطة: يعد عامل الخطاطة في عملية بيان أفعال الكلام عاملاً معرفيَّا لازمًا في الحفاظ على تهيئة المتلقي كي يقدر بالنجاح على تأويل تخربة أو تفسير حادثة أو تحليل خطاب بأسلوب أصيل معتمد. بr وقد أدرج خطابي هذا العامل ضمن آليات تحليل اللغة البشرية الملفوظة وغير الملفوظة، وأثبت أنه من الضروريات المعتمد عليها في لفيل

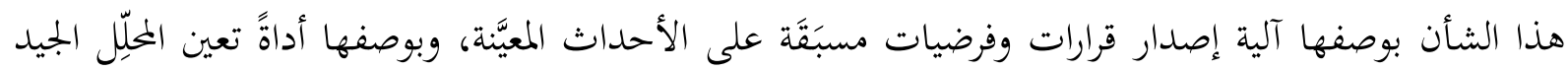
على الاستعداد الناجع بما يتوافر لديه من الطوابع الفطرية والمفاهيم والاعتقادات. 
DOI: https://doi.org/10.22452/aldad.vol5no1.8

e-ISSN: 2637-1146

https://ejournal.um.edu.my/index.php/aldaad/index

\section{References}

'Abd al-Ra'ūf Mafụī Kharabshah. (2005). Manhaj al-Mutakallimīn fì Istinbāt al-Ahkām alShar 'iyyah. Beirut: Dār Ibn Hazm.

Ahmad 'Afīfì. (2001). Naḥwu al-Naṣ: Ittijāh Jadīd fì al-Dars al-Nahwi. Cairo: Maktabah Zahrā' al-Sharq.

Al-Jurjāni, 'Abd al-Qāhir. (2001). Dalā'il al-I'jāz fì 'Ilm al-Ma 'āni. 'Abd al-Hamīd Hindāwi (ed.). Beirut: Dar al-Kutub al-'Ilmiyyah.

Al-Khatīb al-Qazwīni. (2001). Al-Ị̣̄ăh fì 'Ulūm al-Balāghah. 'Abd al-Qādir al-Fāḍilī (ed.)/ Beirut: al-Maktabah al-'Așriyyah.

Al-Nawawi, Abu Zakariyya Yaḥya bin Sharaf al-Dīn. (nd.). Riyād al-Sạliḥinn. Beirut: Mu'assasah al-Risālah.

Ḥāfiz Ibrāhīm. (1937). Dīwān Hāfiz Ibrāhīm. Aḥmad Amīn, Ahmad al-Zayn, Ibrāhīm alAbyāri (ed.). Cairo: Maṭba'ah Dār al-Kutub al-Mișriyyah.

Ibn Taimiah al-Harrāni. (2004). Majmū' al-Fatāwa, Kitāb Ușūl al-Fiqh. Al-Madinah alMunawwarah: Majma‘ al-Malik Fahd Li Ṭibā'ah al-Muṣhaf al-Sharīf.

Klous Brinker. (2005). Al-Taḥlīl al-Lughawi li al-Naṣ: Madākhil ilā al-Mafāhīm al-Asāsiyyah wa al-Manāhij. Sa‘̄̄d Hasan Buhairi. Cairo: Mu’assasah al-Mukhtār li al-Nashr wa al-Tawzi'.

Kristifā. (1991). 'Ilm al-Naș. Farīd al-Zāhī (ed.). Morocco: Dār Topical li al-Nashr.

Mas'ūd Șaḥrāwī. (2005). Al-Tadāwuliyyah 'Ind al-'Ulamā’ al-'Arab. Beirut: Dār al-Ṭal̄̄'ah.

Muhammad Khațạāī. (1991). Lisāniyyat al-Naș: Madkhal ilā Insijām al-Khitāb. Beirut: alMarkaz al-Thaqafi al-'Arabi.

Muhammad Muhammad Abu Musa. (1996). Khāṣa'iṣ al-Tarākīb: Dirāsah Taḥlīliyyah li Masa'il 'Ilm al-Ma'āni. Cairo: Maktabah Wahbah.

Muhammad Tawfīq Muhammad Sa‘ad. (1987). Dilālah al-Alfāz 'Ind al-Ușūliyyìn. Miṣr: Mațba'ah al-Amānah.

Muṣṭafā Nāṣif. (1995). Al-Lughah wa al-Tafsīr wa al-Tawaṣul. Kuwait: al-Majlis al-Waṭani li al-Thaqafah.

Robert Scholz. (1994). Al-Sìmiyā' wa al-Ta'wīl. Sa'īd al-Ghānimi (ed.). 'Ammān: alMu'assasah al-'Arabiyyah li al-Dirāsāt wa al-Nashr. 